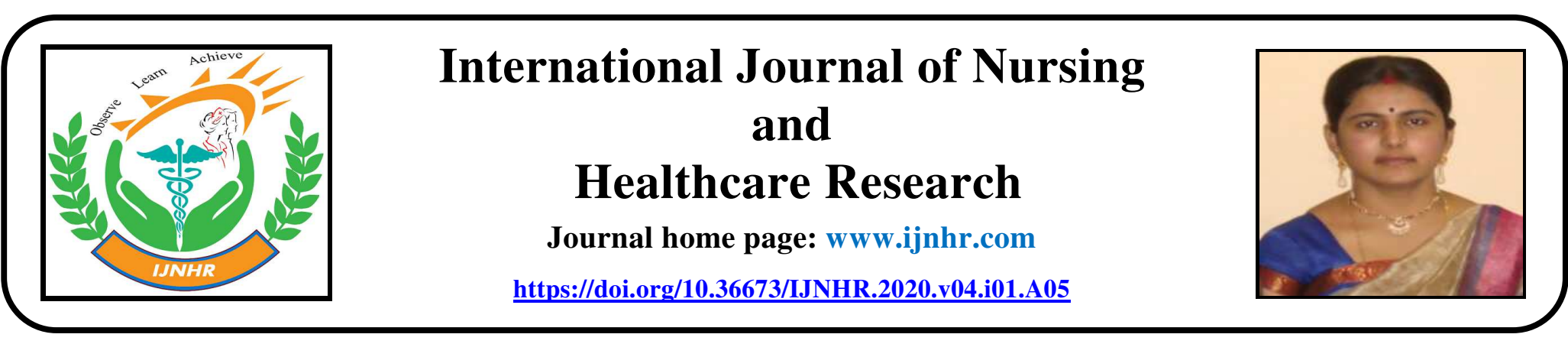

\title{
STUDY TO ASSESS THE KNOWLEDGE, ATTITUDE AND PRACTICE OF BIOMEDICAL WASTE MANAGEMENT AMONG HEALTH PERSONNEL IN SELECTED COMMUNITY HEALTH CENTER
}

\author{
S. M. Asharani*1 and V. G. Veeresh ${ }^{2}$ \\ ${ }^{1 *}$ Staff Nurse, Community Health Center, Kurugodu, Karnataka, India. \\ ${ }^{2}$ Skill Lab Trainer, District Training Center, Raichur, Karnataka, India.
}

ABSTRACT

Background: Biomedical waste carried high risk of infection and it is hazardous. Proper management and handling of biomedical waste is important for all the facilities. The health personnel working in health facility are having inadequate knowledge, negative attitude, and poor practice of biomedical waste management. Objectives: The aim of the study was to assess the knowledge, attitude and practice of biomedical waste management among health personnel and to suggest action for betterment of biomedical waste management. Methodology: A descriptive approach was used, thirty two health personnel includes doctors, nurses, senior health assistant, lab technician, ophthalmic assistant, Group D were selected from community health center, using purposive sampling technique. A structured questionnaire to assess knowledge, attitude and practice having 10 items each was given to collect the data. The data was collected analyzed using SPSS 16.0 version statistical software. Results: The present study found that the health personnel working in community health center had inadequate knowledge positive attitude and good practice towards biomedical waste management. However their practices were not matching the knowledge and attitude. The findings revealed the need for training program on biomedical waste management. Conclusion: The study concluded that the knowledge has to be improved by regular training, the attitude should be changed by soft skill training, behavioral change communication and the practice have to be standardized by understanding and applying the protocols and guideline on biomedical waste management. The study recommended to adapt the changes as per Biomedical Waste Management guidelines 2016 and to follow the amendment of 2018 in managing and handling biomedical waste.

\section{KEYWORDS}

Biomedical waste management 2016, Knowledge, Attitude and Practice.

\section{Author for Correspondence:}

Asharani S M,

Community Health Center,

Kurugodu, Karnataka, India.

Email: veereshvg@gmail.com

\section{INTRODUCTION}

In reducing health problems, treating sick, preventing potential complications of the individual and community, healthcare services and hospitals, laboratories inevitably create waste, which may be hazardous to health. The wastes produced in the 
process of healthcare procedures and activities called Bio-Medical Waste ${ }^{1}$. These biomedical wastes are high potential source of infection and can cause health hazardous. These wastes have to be handled carefully treated scientifically to prevent health hazardous to public. Therefore it becomes essential to have a safe and reliable method for its handling and disposal ${ }^{2}$.

Poor and improper waste management practices pose a huge risk to the health of the patients, health care professionals as well as to the general public besides contributing to the environmental degradation ${ }^{3}$.

It is estimated that about $80-85 \%$ of waste produced in health care settings is non-infectious general waste, $10 \%$ is infectious and the remaining $5 \%$ is other hazardous waste, if the infectious component gets mixed with the general non-infectious waste, the entire bulk of hospital waste may become infectious ${ }^{4}$.

In India alone, around three million tons of health care waste is generated every year and this amount is expected to grow at eight per cent every year ${ }^{5}$.

About 0.33 million tons of hospital waste is generated in India per a year and, the waste generation rate ranges from 0.5 to $2.0 \mathrm{~kg}$ per bed per day ${ }^{1}$. Irrespective of generation of wastes, a safe, reliable method of diosposal and treatment of waste is essential and it is a social responsibility and legal need ${ }^{1}$.

The purpose of biomedical waste are mainly to reduce waste generation, to ensure its efficient collection, handling, as well as safe disposal in such a way that it controls infection and improves safety for employees working in the system ${ }^{6}$.

Comprehensive information, knowledge and skill are needed for proper method to handle wastes and to practice safe disposal. Further, an awareness of proper handling and management of health-care wastes can prevent the spread of infectious diseases and other hazards. With this background, the present study was conducted with the main objective of assessing knowledge, attitude, and practices of health care personnel [Doctor (MBBS, AYUSH, Dental, and Specialist), Nurses, Laboratory technicians, X-ray technician, Pharmacist and Group
D staffs] regarding biomedical waste management at community health center.

\section{METHODOLOGY}

A descriptive design was conducted at selected community health center, a purposive sampling technique was used, total 32 health personnel included doctors, nurses, lab technician, junior health assistant, health workers, group D were samples of the study fulfilled the sampling criteria. The structured questionnaire tool designed to assess the knowledge, attitude and practice of biomedical waste management, which had 10 questions in each respectively. The data was collected and analysis using SPSS 16.0 version.

\section{RESULTS}

\section{Findings related to Socio demographic characteristics of health personnel}

- Age distribution showed that out of 32 health personnel the Mean \pm Standard Deviation was $33.72 \pm 8.62$ years respectively with maximum age was 52 years and minimum age was 22 years.

- Gender distribution showed that out of 32 health personnel $12(37.50 \%)$ were males and $20(62.50 \%)$ were females.

- Level of education showed that out of 32 health personnel 5 doctors, one nurse, one senior health assistant and one group D were graduates; 9 nurses, 6 lab technicians, one ophthalmic assistant were diploma holders; 2 group D were educated till Pre university and 6 group D were educated till high school.

- Nature of work showed that $18(56.25 \%)$ were regular employees and 14(43.75\%) were working as contractual employees.

- Job experience revealed the overall job experience of 32 health personnel Mean \pm Standard Deviation was $8.62 \pm 8.14$ years respectively with maximum of 30 years of experience and minimum score of one-year experience.

- Out of 32 health personnel 3(60.00\%) of doctors, $1(10.00 \%)$ of nurse, $4(66.67 \%)$ of lab technician, and $1(11.11 \%)$ of group D respectively had 
previous training in biomedical waste management and $2(40.00 \%)$ of doctors, $9(90.00 \%)$ of nurses, $1(100.00 \%)$ senior health assistant, $2(33.33 \%)$ of lab technician, $1(100.00 \%)$ of ophthalmic assistant, and $8(88.89 \%)$ of group D respectively had no previous training in biomedical waste management.

- Out of 32 health personnel majority of the them had vaccinated for Hepatitis B 23(71.87\%) and Tetanus Toxide 30(93.75\%) respectively.

Findings related to knowledge of health personnel regarding biomedical waste management

The present study showed the means of knowledge scores was 3.50 with standard deviation 1.43 for total knowledge score of 10, maximum score was 7 and minimum score was 2.

Table No.1 describes that the knowledge score $2(40.00 \%)$ of doctors, $6(60.00 \%)$ of nurses, $1(100.00 \%)$ senior health assistant, 6(100.00\%) of lab technician and $9(100.00 \%)$ of group D respectively their scores were between 1-5 (less than $49 \%$ ) which implied that the knowledge regarding biomedical waste management was inadequate and $3(60.00 \%)$ of doctors, $4(40.00 \%)$ of nurses, one $(100.00 \%)$ of ophthalmic assistant respectively had scored between 5-10 (50\%-100\%) which depicts the that the knowledge regarding biomedical waste management was adequate.

Findings related to attitude of health personnel regarding biomedical waste management

The present study shows the means of attitude scores was 6.16 with standard deviation 1.88 , for total attitude score of 10, maximum score was 9 and minimum score was 3 .

Table No. 2 describes the attitude score $1(20.00 \%)$ of doctors, $4(40.00 \%)$ of nurses, $1(100.00 \%)$ of ophthalmic assistant and $5(55.56 \%)$ of group D respectively their scores were between 1-5 (less than 49\%) which implied that the attitude of health personnel regarding biomedical waste management was dissatisfactory reflects negative attitude and $4(80.00 \%)$ of doctors, $6(60.00 \%)$ of nurses, $1(100.00 \%)$ senior health assistant, $6(100.00 \%)$ of lab technician, and $4(44.44 \%)$ of group D respectively had scored between 5-10 (50\%-100\%) which depicts the that the attitude regarding biomedical waste management was satisfactory reflecting positive attitude.

Findings related to practice of health personnel regarding biomedical waste management

The present study shows the means of practice scores was 5.94 with standard deviation 2.01, for total knowledge score of 10, maximum score was 9 and minimum score was zero.

Table No.3 describes the practice score $1(20.00 \%)$ of doctors, $4(40.00 \%)$ of nurses, $3(50.00 \%)$ of lab technician, $1(100.00 \%)$ of ophthalmic assistant and $6(66.67 \%)$ of group D respectively their scores were between 1-5 (less than 49\%) which implied that the practice level regarding biomedical waste management was poor and $4(80.00 \%)$ of doctors, $6(60.00 \%)$ of nurses, $1(100.00 \%)$ senior health assistant, 3(50.00\%) of lab technician, 3(33.33\%) of group D respectively had scored between 5-10 (50\%$100 \%$ ) which depicts the that the practice level regarding biomedical waste management was good.

\section{DISCUSSION}

\section{Socio demographic characteristics of the health personnel}

The findings of the study shows that out of 32 health personnel the Mean \pm Standard Deviation was $33.72 \pm 8.62$ years respectively with maximum age was 52 years and minimum age was 22 years, range 30 with median 30.50 these finding of the study were similar to finding of the Vijaykumar et al, study $^{7}$ showed that the age of the study participants ranged from 21 to 58 years with a mean of $28.97 \pm 5.99$ years.

Out of 32 health personnel $12(37.50 \%)$ were males and $20(62.50 \%)$ were females, these finding of the present study were contrary to the finding of the Vijaykumar et al, study ${ }^{7}$ where the study had equal number of male and female participants. However in present study majority of them are nurses hence the ratio of females is high in the present study.

Out of 32 health personnel 5 doctors, one nurse, one senior health assistant and one group D were graduates; 9 nurses, 6 lab technicians, one ophthalmic assistant were diploma holders; 2 group 
D were educated till Pre university and 6 group D were educated till high school.

The finding of the study revealed that out of 32 health personnel $18(56.25 \%)$ were regular employees and 14(43.75\%) were working as contractual employees.

The study found that the overall job experience of 32 health personnel Mean \pm Standard Deviation was $8.62 \pm 8.14$ years respectively with maximum of 30 years of experience and minimum score of one year experience, range 33 with median 6.00 these findings were similar to the finding of the Vijaykumar et al, study $^{7}$ in which experience ranged from zero to 30 years with a mean of $3.98 \pm 4.24$ years. The present study findings revealed that doctors, nurses, senior health assistant, lab technician, ophthalmic assistant, and group D had experience of Mean \pm Standard Deviation $7.80 \pm 5.63, \quad 7.40 \pm 7.23, \quad 21 \pm 0.00$, $6.00 \pm 4.42,20 \pm 0.00,9.56 \pm 11.23$ years respectively. The present study finding shows out of 32 health personnel $3(60.00 \%)$ of doctors, $1(10.00 \%)$ of nurse, $4(66.67 \%)$ of lab technician, and $1(11.11 \%)$ of group $\mathrm{D}$ respectively had previous training in biomedical waste management and $2(40.00 \%)$ of doctors, $9(90.00 \%)$ of nurses, $1(100.00 \%)$ senior health assistant, 2(33.33\%) of lab technician, 1(100.00\%) of ophthalmic assistant, and $8(88.89 \%)$ of group D respectively had no previous training in biomedical waste management. This shows that the ratio of untrained is high compare to trained; hence forth there is need for training, workshop, continuing education program about biomedical waste management to health personnel at all level of health care.

The present study finding shows that out of 32 health personnel $23(71.87 \%)$ of them had hepatitis B vaccinated and $9(28.13 \%)$ of them had not protected themselves against hepatitis B disease.

The present study finding shows that out of 32 health personnel $30(93.75 \%)$ of them had tetanus toxide vaccine and $2(6.25 \%)$ of them had not received tetanus toxide vaccine. These finding of the study were in line with the finding of study by Malini et $a l,{ }^{5}$ showed that Majority of the participants in study were immunized against Tetanus and Hepatitis B.
Knowledge of health personnel regarding biomedical waste management

The present study shows that 2 out of 5 doctors; 6 out of 10 nurses; 6 out of 6 lab technician; one senior health assistant; 9 out of 9 Group D personnel had scored less than $49 \%$ which implies that the knowledge of these health personnel was inadequate. These finding of the present study are in line with the finding of the study done by found the poor level of awareness and knowledge on Biomedical waste management among the participants ${ }^{8-10}$ on the other hand 3 out of 5 doctors; 4 out of 10 nurses one ophthalmic assistant had scored between 50\%-100\% which signifies that they have adequate knowledge regarding biomedical waste management. This finding is similar to the finding of study showed that overall knowledge of biomedical waste management was satisfactory among all the health workers ${ }^{4,6,10}$.

Attitude of health personnel regarding biomedical waste management

The present study shows that 4 out of 5 doctors; 6 of 10 nurses; one senior health assistant; 6 out of 6 lab technician; 4 out of 9 group D had scored between $50 \%-100 \%$ which shows satisfactory attitude implies positive attitude, this finding of the present study is similar to the finding of the study done by revealed that doctors were having positive attitude towards biomedical waste management ${ }^{3,11}$ in contrast to this one out of 5 doctors; 4 out of 10 nurses; one ophthalmic assistant; 5 out of 9 group D had scored less than $49 \%$ which implies dissatisfactory revealing negative attitude.

\section{Practice of health personnel regarding biomedical waste management}

The present study shows that 4 out of 5 doctors; 6 out of 10 nurses; one senior health assistant; 3 out of 6 lab technician; 3 out of 9 group D had scored between 50\%-100\% which implies good practice. This findings of the present study was contrary with the finding of the study done by ${ }^{9,4,10}$ showed that poor biomedical waste practice on other hand these findings are similar to present study where 1 out of 5 doctor; 4 out of 10 nurses; 3 out of 6 lab technician; one ophthalmic assistant; 6 out of 9 group D had scored less than $49 \%$ implies the poor practice. 
Asharani S M and Veeresh V G. /International Journal of Nursing and Healthcare Research. 4(1), 2020, 27-33.

Table No.1: Describes the knowledge scores of Health personnel $\mathbf{n}=32$

\begin{tabular}{|c|c|c|c|c|c|c|c|c|c|c|c|c|c|}
\hline \multirow[t]{2}{*}{ S.No } & \multirow{2}{*}{$\begin{array}{c}\text { Knowledge } \\
\text { Level }\end{array}$} & \multicolumn{2}{|c|}{ Doctors } & \multicolumn{2}{|c|}{ Nurses } & \multicolumn{2}{|c|}{$\begin{array}{c}\text { Senior Health } \\
\text { Assistants }\end{array}$} & \multicolumn{2}{|c|}{$\begin{array}{c}\text { Lab } \\
\text { Technicians }\end{array}$} & \multicolumn{2}{|c|}{$\begin{array}{c}\text { Ophthalmic } \\
\text { Assistant }\end{array}$} & \multicolumn{2}{|c|}{ Group D } \\
\hline & & $\mathbf{N}$ & $\%$ & $\mathbf{N}$ & $\%$ & $\mathbf{N}$ & $\%$ & $\mathbf{N}$ & $\%$ & $\mathbf{N}$ & $\%$ & $\mathbf{N}$ & $\%$ \\
\hline 1 & Inadequate & 02 & 40.00 & 06 & 60.00 & 01 & 100.00 & 06 & 100.00 & 00 & 0.00 & 09 & 100.00 \\
\hline 2 & Adequate & 03 & 60.00 & 04 & 40.00 & 00 & 0.00 & 00 & 0.00 & 01 & 100.00 & 00 & 0.00 \\
\hline 3 & Total & 5 & 100.00 & 10 & 100.00 & 1 & 100.00 & 6 & 100.00 & 1 & 100.00 & 9 & 100.00 \\
\hline
\end{tabular}

N-Frequency, \%-Percentage, N-Total health personnel

Table No.2: Describes the attitude scores of Health personnel $n=32$

\begin{tabular}{|c|c|c|c|c|c|c|c|c|c|c|c|c|c|}
\hline \multirow[t]{2}{*}{ S.No } & \multirow{2}{*}{$\begin{array}{c}\text { Attitude } \\
\text { Level }\end{array}$} & \multicolumn{2}{|c|}{ Doctors } & \multicolumn{2}{|c|}{ Nurses } & \multicolumn{2}{|c|}{$\begin{array}{c}\text { Senior Health } \\
\text { Assistants }\end{array}$} & \multicolumn{2}{|c|}{$\begin{array}{c}\text { Lab } \\
\text { Technicians }\end{array}$} & \multicolumn{2}{|c|}{$\begin{array}{c}\text { Ophthalmic } \\
\text { Assistant }\end{array}$} & \multicolumn{2}{|c|}{ Group D } \\
\hline & & $\mathbf{N}$ & $\%$ & $\mathbf{N}$ & $\%$ & $\mathbf{N}$ & $\%$ & $\mathbf{N}$ & $\%$ & $\mathbf{N}$ & $\%$ & $\mathbf{N}$ & $\%$ \\
\hline 1 & Negative & 01 & 20.00 & 04 & 40.00 & 00 & 0.00 & 00 & 0.00 & 01 & 100.00 & 05 & 55.56 \\
\hline 2 & Positive & 04 & 80.00 & 06 & 60.00 & 01 & 100.00 & 06 & 100.00 & 00 & 0.00 & 04 & 44.44 \\
\hline 3 & Total & 5 & 100.00 & 10 & 100.00 & 1 & 100.00 & 6 & 100.00 & 1 & 100.00 & 9 & 100.00 \\
\hline
\end{tabular}

$\mathrm{N}$-frequency, \%-Percentage, $\mathrm{n}$-Total health personnel

Table No.3: Describes the practice score of Health personnel $n=32$

\begin{tabular}{|c|c|c|c|c|c|c|c|c|c|c|c|c|c|}
\hline \multirow[t]{2}{*}{ S.No } & \multirow{2}{*}{$\begin{array}{c}\text { Practice } \\
\text { Level }\end{array}$} & \multicolumn{2}{|c|}{ Doctors } & \multicolumn{2}{|c|}{ Nurses } & \multicolumn{2}{|c|}{$\begin{array}{l}\text { Senior Health } \\
\text { Assistants }\end{array}$} & \multicolumn{2}{|c|}{$\begin{array}{c}\text { Lab } \\
\text { Technicians }\end{array}$} & \multicolumn{2}{|c|}{$\begin{array}{c}\text { Ophthalmic } \\
\text { Assistant }\end{array}$} & \multicolumn{2}{|c|}{ Group D } \\
\hline & & $\mathbf{N}$ & $\%$ & $\mathbf{N}$ & $\%$ & $\mathbf{N}$ & $\%$ & $\mathbf{N}$ & $\%$ & $\mathbf{N}$ & $\%$ & $\mathbf{N}$ & $\%$ \\
\hline 1 & Poor & 01 & 20.00 & 04 & 40.00 & 00 & 0.00 & 03 & 50.00 & 01 & 100.00 & 06 & 66.67 \\
\hline 2 & & 04 & 80.00 & 06 & 60.00 & 01 & 100.00 & 03 & 50.00 & 00 & 0.00 & 03 & 33.33 \\
\hline 3 & Total & 5 & 100.00 & 10 & 100.00 & 1 & 100.00 & 6 & 100.00 & 1 & 100.00 & 9 & 100.00 \\
\hline
\end{tabular}

$\mathrm{N}$-frequency, \%-Percentage, n-Total health personnel

Table No.4: Describes the knowledge, attitude, practice of Health personnel $n=32$

\begin{tabular}{|c|c|c|c|c|c|c|c|c|c|c|}
\hline \multirow{2}{*}{ S.No } & Aspect & \multicolumn{3}{|c|}{ Knowledge } & \multicolumn{3}{c|}{ Attitude } & \multicolumn{3}{|c|}{ Practice } \\
\cline { 2 - 12 } & $\begin{array}{c}\text { Pealth } \\
\text { Personnel }\end{array}$ & Mean & $\begin{array}{c}\text { Standard } \\
\text { Deviation }\end{array}$ & Mean\% & Mean & $\begin{array}{c}\text { Standard } \\
\text { Deviation }\end{array}$ & Mean \% & Mean & $\begin{array}{c}\text { Standard } \\
\text { Deviation }\end{array}$ & Mean \% \\
\hline 1 & Doctors & 5.00 & 1.58 & 21.58 & 7.20 & 1.92 & 19.42 & 6.00 & 1.58 & 17.56 \\
\hline 2 & Nurses & 3.00 & 1.65 & 15.10 & 5.90 & 1.96 & 15.42 & 6.40 & 1.57 & 18.72 \\
\hline 3 & $\begin{array}{c}\text { Senior Health } \\
\text { Assistant }\end{array}$ & - & 0.00 & 17.27 & 9 & 0.00 & 23.98 & 5 & 0.00 & 14.62 \\
\hline 4 & $\begin{array}{c}\text { Lab } \\
\text { Technician }\end{array}$ & 2.50 & 0.81 & 11.52 & 7.33 & 0.51 & 19.54 & 8.00 & 0.63 & 23.40 \\
\hline 5 & $\begin{array}{c}\text { Ophthalmic } \\
\text { Assistant }\end{array}$ & - & 0.00 & 21.58 & 3 & 0.00 & 8.00 & 4 & 0.00 & 11.70 \\
\hline 6 & Group D & 3.00 & 0.86 & 12.95 & 5.11 & 1.45 & 13.64 & 4.78 & 1.39 & 14.00 \\
\hline \multicolumn{2}{|c|}{ Over All Scores } & 3.50 & 1.43 & 100.00 & 6.16 & 1.88 & 100.00 & 5.94 & 2.01 & 100.00 \\
\hline
\end{tabular}




\section{RECOMMENDATIONS}

Based on the findings of the present study the recommendations can be:

1. Similar study can be studied with intervention and control group.

2. Large sample can be used to for generalization.

3. To cover large population manuals, information booklets and self-instructional modules may be developed and published or distributed included information on category, segregation, collection, transport and treatment.

4. An interventional study can be conducted using Video Assisted Teaching instead of planned teaching program, which helps better learning outcome.

5. The policy makers and administrators can plan for training or continuing education program for medical, nursing, paramedical and group $\mathrm{D}$ to upgrade the quality application of biomedical waste management at all levels of health care facility, which helps in prevention of hospital infections.

6. The administrative officers can be given suggestion to take action for improvement as per the Biomedical Waste Management rules 2016 and amendment 2018.

A better biomedical waste management can be achieved by regular training health personnel about soft skills, behavioral change communication, continuous monitoring, constant regular peer review, monitoring and maintain biomedical waste management standards as per protocol and BMW 2016 guidelines.

\section{CONCLUSION}

The main aim of the study was to assess the knowledge, attitude and practice regarding biomedical waste management among health personnel and to describe the knowledge level, understand the attitude and to identify the practice of biomedical waste management. Data collected using structured knowledge, attitude and practice questionnaire from thirty-two health personnel included doctors, nurses, senior health assistant, lab technicians, ophthalmic assistant and group D who were willing to participate in the study. Collected data was analyzed for descriptive statistics, the means of knowledge scores was 3.50 with standard deviation 1.43, for total knowledge score of 10 , maximum score was 7 and minimum score was 2 with range 5. The means of attitude scores was 6.16 with standard deviation 1.88 , for total attitude score of 10, maximum score was 9 and minimum score was 3 with range 6 . The means of practice scores was 5.94 with standard deviation 2.01, for total knowledge score of 10, maximum score was 9 and minimum score was zero with range 9 .

The present study showed that the health personnel were having inadequate knowledge, positive attitude and good practice regarding biomedical waste management. However the project identified that there was poor practice of biomedical waste management which can be modified to good practice by regular training, workshops, seminars, soft skills development, behavioral change communication to health personnel regarding biomedical waste management to bring the up the hospital image and prevent the infection and spread of infectious diseases.

\section{ACKNOWLEDGEMENT}

The authors wish to express their sincere gratitude to Community Health Center Kurugodu, Karnataka, India for providing necessary facilities to carry out this research work.

\section{CONFLICT OF INTEREST}

We declare that we have no conflict of interest.

\section{BIBLIOGRAPHY}

1. Patil A D, Shekdar A V. Health-care waste management in India, $J$ Environ Manage, 63(2), 2001, 211-220.

2. Park K. Park's Text book of Preventive and Social Medicine, M/s Banarasidas Bhanot Publishers, Jabalpur, $23^{\text {rd }}$ Edition, 2015, 789.

3. Kaur D C, Pandey A, Tekwani D, Bedekar M Y, Pai M, Agarwal M. Awareness of Biomedical waste management among the health care workers in rural area, Indian Journal of Basic and Applied Medical Research, 4(4), 2015, 351-357. 
4. Bansal M, Mishra A, Gautam P, Changulani R, Srivastava D, Gour N S. Biomedical waste Management: Awareness and practices in a district of Madhya Pradesh, Natl J Community Med, 2(3), 2011, 452-456.

5. Malini A, Eshwar B. Knowledge, Attitude and Practice of Biomedical waste management among health care personnel in a tertiary care hospital in Puducherry, Intl J of Biomed Res, 6(3), 2015, 172-176.

6. Chudasama R K, Rangoonwala M, Sheth A, Misra S K C, Kadri A M, Patel U V. Biomedical Waste Management: A study of knowledge, attitude and practice among health care personnel at tertiary care hospital in Rajkot, J Res Med Den Sci, 1(1), 2013, 17-22.

7. Vijaykumar Mane, Smita M, Nimbannavar, Yuvaraj B Y. Knowledge, attitude and practices on biomedical waste and its management among health care workers at a tertiary care hospital in Koppal, Karnataka, India, Int J Community Med Public Health, 3(10), 2016, 2953-2957.

8. Patil S P, Tambe M P, Patil P J, Bhagwat V R. Awareness of health care worker regarding Bio-medical waste management at tertiary care government hospital in Dhule (Maharashtra), Natl J Integrate Res Med, 4(4), 2013, 74-79.

9. Sharma A, Sharma V, Sharma S, Singh P. Awareness of Biomedical Waste Management among Health care personnel in Jaipur, India, Oral. Hea and Den. Mgt, 12(1), 2013, 32-40.

10. Ajai S, Nath S R. Knowledge, attitude and practices of biomedical waste management amongst staff of institutional trauma center level II, Inter Jour of Res in Heal Sci, 1(2), 2013, 62-68.

11. Sachan R, Patel M L, Nischal A. Assessment of the knowledge, attitude and practices regarding Biomedical Waste Management amongst the Medical and Paramedical staff in Tertiary Health care Center, Interna Jour of Scient and Res Publi, 2(7), 2012, 1-6.

Please cite this article in press as Asharani S M and Veeresh V G. Study to assess the knowledge, attitude and practice of biomedical waste management among health personnel in selected Community Health center, International Journal of Nursing and Healthcare Research, 4(1), 2020, 27-33. 